\title{
OPEN INNOVATION IN MANUFACTURING SMES - INTEGRATION INTO VALUE NETWORKS
}

\author{
Angela Fajsi ${ }^{\mathrm{a}}$, Željko Tekića $^{\mathrm{ab}}$, Slobodan Morača ${ }^{\mathrm{a}}$ \\ ${ }^{a}$ University of Novi sad, Faculty of Technical Sciences, Trg Dositeja Obradovića 6, 21000 Novi Sad, Republic of Serbia \\ ${ }^{b}$ Skolkovo Institute of Science and Technology, Center for Entrepreneurship and Innovation, Nobel Street 3, 143026 \\ Moscow, Russian Federation
}

\begin{abstract}
In constantly changing market, small and medium enterprises (SMEs) highly rank importance of collaboration through the entire value network. Due to their size and to limitations they face, the problem of harmonization of their business processes with research and development is particularly emphasized, especially in terms of necessity of using both internal and external resources.

The purpose of this paper is to examine the effects of value networks participants' collaboration to Open Innovation (OI). SMEs, especially the ones from the manufacturing sector, came to realize that rigid market demands and new technologies go beyond individual companies. Thus, innovation companies are forced to share ideas and resources with other participants in complex value networks where research, development and production are treated as open system. The paper presents authors' initial findings, which are the basis for further research planned for first-author's PhD dissertation.
\end{abstract}

Keywords: open innovation, manufacturing, SMEs, collaboration, value network
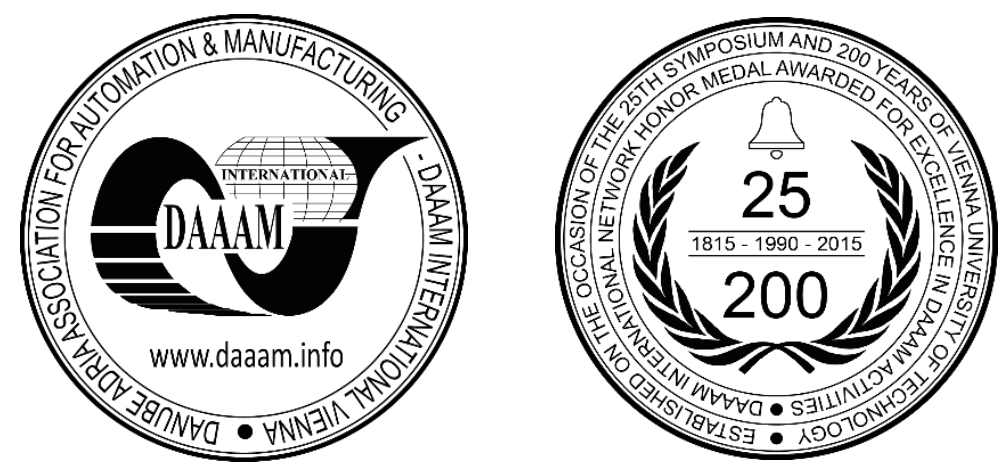

This Publication has to be referred as: Fajsi, A[ngela]; Tekic, Z[eljko] \& Moraca, S[lobodan] (2016). Open Innovation in Manufacturing SMEs - Integration into Value Networks, Proceedings of the 26th DAAAM International Symposium, pp.1076-1081, B. Katalinic (Ed.), Published by DAAAM International, ISBN 978-3-902734-07-5, ISSN 1726-9679, Vienna, Austria

DOI: $10.2507 / 26$ th.daaam.proceedings.151 


\section{Introduction}

Small and medium-sized enterprises (SMEs) play a significant role in global socio economic development. In developed countries, manufacturing SMEs are considered to be the main engine of economic growth, but in developing countries they can also have significant socio-economic effects. According to the European Commission, SMEs are a major source of employment, with special focus on encouraging innovations and strengthening the entrepreneurial spirit $[1]$.

When it comes to open innovation in manufacturing SMEs, they experience certain challenges [2]. Firstly, SMEs are facing the problem of lower absorptive capacities - lack of resources for building organizational, production and personnel structures for identifying external knowledge. Sometimes external ideas and technologies are identified and recognized, but many SMEs do not have personnel with required scientific background to understand and exploit that knowledge [3]. Another challenge is directly related to external environment- innovation process that is not institutionalized makes SMEs unattractive as potential partners of large companies. The ability to profit from intellectual property is often limited [4] because smaller companies economically depend on large companies.

The purpose of this paper is to theoretically investigate the effects of value network environment to Open innovation, in particular relations among SMEs, large companies and other value network participants, and to propose directions for the further research. Nowadays, the highest priority in achieving competitive advantage is innovation, hence, business networks are becoming essential elements for knowledge economy development.

This paper is organized as follows - in the second chapter, Open innovation concept and its most important elements are introduced. This chapter also covers value network, necessary for SMEs' collaboration and in achieving competitive advantage. Innovation is nowadays opening for all value network participants. Following this, third chapter investigates relationship between small and large companies in the terms of open innovation, and defines benefits for other network participants. Considering this, authors reviewed effects of this collaboration to open innovation environment in developed economies and made implications for further research relevant to developing countries.

\section{Open innovation: Literature overview}

\subsection{Theory of open innovation}

In the past, many companies were able to effectively run a business, even with insignificant investment in innovation. Industrial manufacturing sector was not considered as one of the leading innovators [5]. Due to globalization and outsourcing, increased need for improved efficiency and productivity appeared. Innovation has become one of the primary tools for differentiating companies from their competitors. Achieving added value through innovation seems to be deliberate choice of many companies.

Building a new industrial system takes more than one company or one organization. Closed innovation systems are being replaced with open innovation systems. In the last several years, open innovation has become very important for both theory and practice development.

Chesbrough implied that valuable and innovative ideas might be created from the inside and from the outside of the company [6], and he is defined open innovation as "a paradigm that assumes that firms should and can use external ideas as well as internal ideas, and internal and external path to market, as they look to advance their technology" [7].

This new research paradigm is based on the opinion that it is not possible that all intelligent people, from one particular field, work for the same company [7]. It is necessary to find, and explore knowledge and expertise of people outside of company. The real winners in open innovation process are organizations that use both internal and external ideas and resources, in order to create the best idea for their own company, and environment.

Gassmann and Enkel defined three core open innovation processes [8] in development and production: OutsideIn Process, Inside-Out Process and Coupled Process, as it is illustrated in Figure 1.

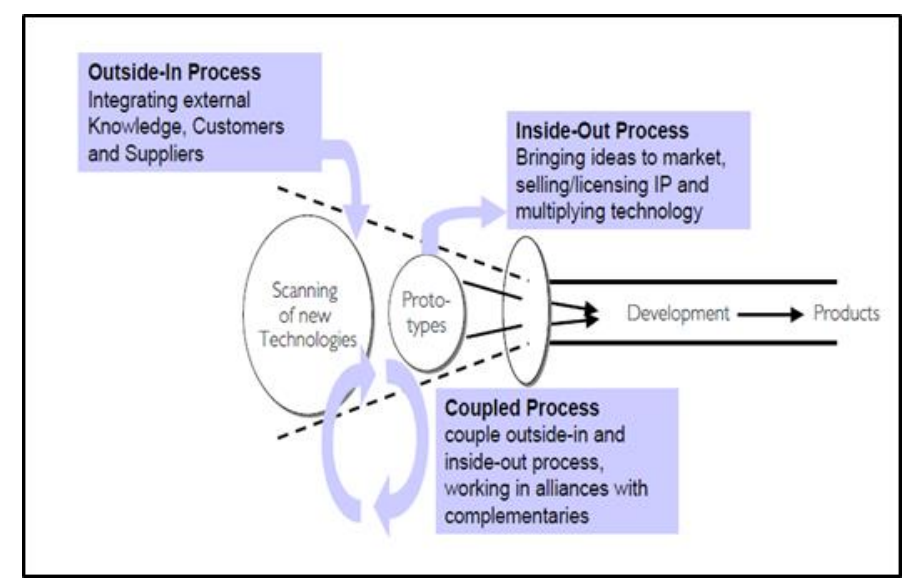

Fig. 1. Three archetypes of open innovation processes [8] 
On the contrary, some scholars [9] [10] state that open innovation has two dimensions: inbound and outbound open innovation. Inbound open innovation considers knowledge acquisition and technology purchasing to be of important contributors to the internal innovation process, due to shortened time from idea to market and to minimized internal R\&D costs. Outbound open innovation is oriented towards in-house research and development through external exploitation of knowledge [10]. In other words, inbound open innovation implies that external knowledge flows inside the firm, and in outbound open innovation knowledge flows outside the firm.

Innovation concept has been formerly examined at the individual company level with special focus on the technological aspect [7] [11]. Inter-company collaboration for innovation appeared as the industrial response to changes in economic and technological conditions [12].

\subsection{Synergism of innovating and collaborating in a networked environment}

Networked business environment had been based on the value chain model, aimed at creating value for the customer i.e. users. A typical supply chain includes inbound logistics, work processes, outbound logistics, marketing, sales and servicing [13]. Suppliers and partner organizations oriented towards product or service delivery to the customer are in the center of supply chain. The value creation process could be partially explained through supply chain model. However, this model is a characteristic for traditional industrial systems, and it changes in the knowledge economy.

The value is being replaced with value network. Value network generates economic value through a complex dynamic exchange between one or more companies, customers, suppliers, strategic partners and the community. The role of these networks can be seen as much more than just a way of transaction of goods, services and income, it is based on knowledge and intangible values [14].

Normann and Ramirez define Value networks as "inter-organizational networks which are linking firms with different assets and competencies together in response to or in anticipation of new market opportunities' "[15].

Creation of the new value is possible if the company collaborates with other parties, and creates a new business model. This new business model has to identify different sources of value creation or 'value drivers'. Value creation is not only about adding value to the each step of business process, but also reconfiguration of the roles and relationships throughout the entire value chain [8] [15].

Instead of limiting innovation to what companies can devise within their own borders, pull systems open innovation processes to many diverse participants, whose input can take product and service offerings in unexpected directions that serve a much broader range of needs [16]. This kind of value network approach describes co-creation, usually defined as the involvement of customers in innovation processes, while creating mutual value [17][18]. However, potential co-creators can also come from academia (students and researchers) and industry (partners, competition) [19][20]. Therefore, co-creation, as a networked approach, drives an evolution in the market, as well as generation of new knowledge in business, academia, and practice [21].

\section{SMEs and open innovation in manufacturing : Relations with large companies in a networked environment}

SME sector had rapid and significant growth in the last 30 years. Flexibility and specific characteristics of SMEs represent advantage in the accelerating innovation. The research done by Stanislawski and Lisowka founds a significant percentage share of innovative enterprises by main type of innovation activities [22], as it illustrated in Table 1.

\begin{tabular}{lc}
\hline \multicolumn{1}{c}{ SMEs innovation activities } & SMEs companies share (\%) \\
\hline Marketing market observations & 41.2 \\
Creativity of employees and management & 57.14 \\
Company's own R\&D & 34.9 \\
Support from business environment & 52.3 \\
institutions & 58.7 \\
Purchase of patents, licenses, knowledge & 23.8 \\
Sale of patents, licenses, knowledge & \\
\hline
\end{tabular}

Table 1. SMEs' open share in innovation activities [22]

Most of respondents have sufficient capacity to manage the whole innovation process by themselves, and this encourages them to collaborate with other companies [5]. On the other hand, SMEs usually have limited financial and personnel resources, and this raises the question of how do companies innovate in turbulent environments. SMEs problems regarding capacities are fully or partly solved by networking with other companies and institutions [14]. SMEs in networked environment are encouraged to use external resources in order to reduce risks, to shorten innovation time and costs, and to increase flexibility of operational activities in network [5] [23]. The central roles in this kind of business network have both SMEs and large companies. 
Open innovation can produce number of benefits at the company level, especially in large companies e.g. Procter \& Gamble, Xerox, Philips, etc. [3].

Large companies are more oriented towards their own internal projects where external knowledge flows inside the company, rather than to developing knowledge that flows outside the company. Projects with an inbound component have average share of $35 \%$ in the total number of projects, and only about $8 \%$ of projects result in outbound activities [24]. The leading inbound practices in large companies are university research grants, informal networking and customer co-creation [13] [24]. In large companies internal projects are sometimes commercialized on new markets. Outbound activities play a secondary role in open innovation of large companies. Joint ventures are the most important outbound practices.

For example, General Motors (GM) and ABB Ltd. recently completed a two-year joint research project, that was investigating and analyzing the potential of using battery packs from plug-in hybrid Chevy Volts to power the grid[3]. GM has used the concept of open innovation in the last several years. Closed business environment requires large quantities of resources, but spending more does not always mean innovating better. Another example is General Electric (GE), which is fostering collaboration not only with innovative companies but also with universities and research institutions. GE has launched FirstBuild, a microfactory and open community space in Louisville, designed for students and engineers to cooperate in the creation of smart equipment [25]. This company wants to establish a new business model for the manufacturing industry using the open innovation model, and by supporting community involvement to build radical new products.

Companies which would like to catch up with top innovators need to enhance collaboration, and to include public and private initiatives. Small companies could get a number of benefits participating in open innovation process. When it comes to large companies, they have strategic objectives to engage in open innovation: establishing new partnerships, exploring new technological trends, identifying new business opportunities, accelerating time to complete R\&D [26].

SMEs have several advantages over large companies. Smaller companies are more oriented to small markets that are not attractive for large companies. In that way, they could exploit new trends with lower costs. SMEs are often focused on specific market area, customer type, technology, and if customers value their expertise, they could achieve competitive advantage. In addition, smaller companies can react more quickly to customer requirements; they make decisions faster and implement them more rapidly [3].

In the research done by $\mathrm{PwC}$ [27], most of industrial manufacturing representatives (95\%) say their companies have plans to enhance collaboration with strategic partners over the next three years, and $48.8 \%$ co-created with external partners. In the recent years, trends of networking and collaboration have shown to have a tendency towards more collaboration across industry sectors.

Creating an environment that supports innovation is not a simple task. The research found that $45 \%$ of industrial manufacturing respondents agreed with the fact that creating an innovative environment represented a challenge for them [21]. One reason why companies collaborate with each other is technological complexity [11]. New technologies that are used in manufacturing, like additive manufacturing and Internet 4.0, may have had a significant impact on the direction of innovation efforts [27].

Large companies have a range of constraints and challenges that limit them to garner the benefits of open innovation. According to the research conducted by Fraunhofer institute, companies consider organizational change to be the most significant challenge (the mark: 5.6 on the scale from 1 to 7) [24]. The most critical challenges for both SMEs and large companies are related to transition period from closed to open innovation internally, as well as establishment of external relationships with innovation partners. Some of the biggest innovation challenges for industrial manufacturing companies are taking innovative ideas to market quickly and in a scalable way (45\% of the respondent companies) and finding the right external partners to collaborate with (43\%) [27].

\subsection{Benefits to other participants in networked environment}

Many scholars state that companies which have close relationships with, suppliers, customers, business partners, research institutions, and competitors, are more likely to have higher product and process innovation success [28] [29]. Such kind of business network environment was introduced as the answer to the challenges of globalization, where companies have a central role in the new product development and in process of value creation. Other network participants are defined "as network players whose presence in network can influence value creation of the firm" [30], such as customers, research institutions, regulators, and other support organizations.

All participants have strategic objectives to engage in open innovation process. In the value network, customers have an opportunity to interact with other participants in order to co-create value [31], and to design, personalize and customize products for their own need. University-industry collaboration has its own benefits for both parties. Jung and Andrew distinguished three kinds of benefits: economic, institutional and social benefits [32]. This kind of collaboration brings number of benefits for industry, such as cost-effective research than similar in house research, improved innovative ability and capability, accelerating commercialization of technologies, etc. Universities play a key role in innovative networked environment; hence, they garner significant benefits of innovation openness, e.g. providing additional financial sources to researchers, stimulation of development of spin-offs, enhancement of university's reputation [32].

The era of open innovation has just begun [33], all participants in value network need to be identified and involved in open innovation process throughout the entire network, especially in less performing countries. Changing 
technological and commercial environment in these countries mean that open innovation methods and techniques must be learnt as soon as possible. Open innovation and co-creation are among key trends which are reshaping the future of manufacturing [34].

\section{Summary of findings and implications}

This study describes innovation process in open environment that reflect different patterns of network participants' engagement. The findings imply the importance of creating an innovative environment that allows the development and the production of highly customized products in accordance with specific requirements of the customer, in the shortest possible time and with the lowest cost. This seems to be one of the main trends in the industry [27].

Creating open innovation environment can enable the exchange of information, assistance in developing and establishing business partnerships, access to modern technologies and knowledge (Key Enabling Technologies (KET), Agile technology, Lean Manufacturing, Total Quality Management), support in the creation of innovative solutions, projects and products.

Our future research will build on these findings and explore effects of innovation framework conditions in terms of developing linkages between SMEs, large companies, R\&D institutions, public sector and end users.

\section{Conclusion}

In challenging global economy, SMEs are coping with both small and large company competitors. However, small and medium companies still have some advantages over large companies and should not see them only as competitors. Companies are experiencing pressure in terms of shortened time from idea to application, and increased product complexity by using of advanced technologies. They realized that they can no longer rely sole on their own R\&D, so they have to acquire ideas from other companies and institutions. It is evident that small companies need large, and large companies need small, but open innovation circle is not yet closed.

This paper has reviewed the literature on the open innovation in value networks with special focus on relations and impact between SMEs and large companies. Relationship and impact between Open innovation and the innovation potential of other value network participants that operate in less performing regions is the interesting research field in the future.

The Value Network provides opportunity to integrate innovative capacities of all participants, both research and industrial, to improve and stimulate the realisation of the comprehensive industrial potential of SMEs, to create new value for SMEs and other stakeholders by boosting their research and innovation potential, and to reorganise human and material resources in the Network.

Further research is going to be focused on giving the answers to the following questions: How can each value network participant increase the benefits of open innovation in less performing regions? How value networks participants' collaboration function under these circumstances?

Series of case studies on examining value network participant's collaboration to open innovation in less performing regions need to be taken, and this research is going to be basis for author's PhD dissertation.

\section{Acknowledgements}

This work was partially supported by the Ministry of Education, Science and Technology Development of the Republic Serbia under Grant number TR-35050, for the period 2011-2015.

\section{References}

[1] European Commision. A recovery on horizon. Annual report on European SMEs 2012/2013 (2013)

[2] V. Van de Vrande, J. P. J. De Jong, W.Vanhaverbeke, M. De Rochemont, Open innovation in SMEs: Trends, motives and management challenges, Technovation. 29 (2009) 423-437.

[3] H. Chesbrough. Cover story. Open Innovation: A Key to Achieving Socioeconomic Evolution.How Smaller Companies Can Benefit from Open Innovation. $2010 \quad$ [Online] Available: http://static2.inovacaoedesign.com.br/artigos_cientificos/how_smaller_companies_can_benefit.pdf

[4] S. Cohen, N. Kaimenakis, Intellectual capital and corporate performance in knowledge-intensive SMEs, The Learning Organization, 14 (2007) 241-262.

[5] S. Lee, G. Park, B. Yoon, J. Park, Open innovation in SMEs-An intermediated network model, Research Policy. 39(2010) 290-300.

[6] H. Chesbrough, Open innovation: a new paradigm for understanding industrial innovation, Open Innovation: Researching a New Paradigm. (2006) 1-12.

[7] H. Chesbrough, The logic of open innovation: managing intellectual property, California Management Review. 45(2003) 33-58.

[8] O. Gassmann, E. Enkel, Towards a theory of open innovation: three core process archetypes, In R\&D management conference. 6 (2003) 1-18. 
[9] F. Michelino, M. Caputo, A. Cammarano, E. Lamberti, Inbound and outbound open innovation: organization and performances, Journal of Technology Management \& Innovation. 9(2014) 65-82.

[10] I.Savitskaya, M. Ihrig, Exploring Open Innovation Strategies: A Simulation Approach, In ECMS (2003) 71-77

[11] W. Vanhaverbeke, M. Cloodt, Open innovation in value networks, Open Innovation: Researching a New Paradigm. (2006) 258-281.

[12] H. L. Smith, K. Dickson, S. L. Smith, There are two sides to every story: Innovation and collaboration within networks of large and small firms, Research Policy. 20 (1991) 457-468.

[13] M. Jacob, M. Lundqvist, H. Hellsmark, Entrepreneurial transformations in the Swedish University system: the case of Chalmers University of Technology, Research Policy. 32 (2003) 1555-1568.

[14] M. E. Porter, V. E. Millar, How information gives you competitive advantage, Harvard Business Review, Reprint Service. (1985).

[15] H. Håkansson, Corporate technological development: cooperation and networks. London: Routledge. (1989).

[16]J. S. Brown, J. Hagel, From push to pull: The next frontier of innovation. 2005. [Online]. Available: http://www.mckinseyquarterly.com/Strategy/Strategic_Thinking/From_push_to_pull_The_next_frontier_of_innov ation_1642?gp=1.

[17] C. Prahalad, V. Ramaswamy, Co-creation experiences: The next practice in value creation. Journal of Interactive Marketing. 18 (2004) 5-14

[18] A. F. Payne, K. Storbacka, P. Frow, Managing the co-creation of value. Journal of the Academy of Marketing Science. 36 (2008) 83-96

[19] S. Schoellhammer, A. Orcik, The Uebermorgenwerkstatt: Co-creating a shared, customizable innovation process for collaborative development projects, in 21st International Product Development Management Conference "Innovation through Engineering, Business \& Design," 2014.

[20] P. Vrgovic, A. Tekic, Z. Tekic, M. Medojevic, D. Ciric, V. Todorovic, Students as Innovation Partners - Company Insights from South-East Europe, in The 8th International Conference for Entrepreneurship, Innovation and Regional Development - ICEIRD 2015, 2015.

[21] A. Orcik, Z. Tekic, Z. Anisic, Customer Co-Creation throughout the Product Life Cycle, International Journal of Industrial Engineering and Management. 4 (2013) 43-49

[22]R.Stanisławski, R.Lisowski, The Relations between Innovation Openness (Open Innovation) and the Innovation Potential of SMEs, Procedia Economics and Finance. 23 (2015) 1521-1526.

[23] J. Hagerdoorn, Understanding the rationale of strategic technology partnering: interorganizational modes of cooperation and sectoral differences, Strategic Management Journal. 14 (1993) 371-386.

[24] H. Chesbrough, Managing open innovation in large firms, Executive Survey on Open Innovation. 2013. [Online] Available: innovation.pdf

[25] L. Gilpin, GE launches 'microfactory' to co-create the future of manufacturing. [Online] Available: http://www.techrepublic.com/article/ge-launches-microfactory-to-co-create-the-future-ofmanufacturing/\#ftag=RSS56d97e7

[26] S.Talluri, R. C.Baker, J. Sarkis, A framework for designing efficient value chain networks, International Journal of Production Economics. 62 (1999) 133-144.

[27] PWC.Rethinking innovation in industrial manufacturing Are you up for the challenge? [Online] Available: $\mathrm{http}: / / \mathrm{www}$.pwc.com/gx/en/industrial-manufacturing/publications/pdf/pwc-rethinking-innovation-in-industrialmanufacturing-are-you-up-for-the-challenge.pdf

[28] R.Normann, R. Ramirez, Designing interactive strategy, Harvard Business Review. 71(1993) 65-77.

[29] T. Ritter, H. G.Gemünden, Network competence: Its impact on innovation success and its antecedents, Journal of Business Research. 56 (2003) 745-755.

[30] J.Peppard, A. Rylander, From value chain to value network: Insights for mobile operators, European Management Journal. 24 (2006) 128-141.

[31] C. K. Prahalad, V. Ramaswamy, Co-creating unique value with customers, Strategy \& Leadership. 32 (2004) 4-9.

[32] K.Jung, S.Andrew, Building R\&D collaboration between university-research institutes and small medium-sized enterprises, International Journal of Social Economics. 41 (2014) 1174-1193.

[33] O. Gassmann, E. Enkel, H. Chesbrough, The future of open innovation, R\&D Management. 40 (2010) $213-221$.

[34] I. Cosic, B.Katalinic, Z. Tekic, B.Lalic, Reshaping the future of manufacturing - five trends for the next ten years, in 12th International scientific conference MMA Flexible Technology, 2015 